\title{
La escena alternativa de los editores independientes
}

Uberto Stabile

Entendemos que el desarrollo experimentado por

Ela sociedad española en los últimos años ha permitido un crecimiento en el hábito de consumo de productos culturales, así como un espectacular avance en los procesos de reproducción y acceso de la población a estos medios. En las últimas dos décadas la sociedad civil ha sido capaz de generar una oferta cultural propia e independiente, oferta que no encuentra su lugar en los circuitos comerciales convencionales, ni cuenta con el debido apoyo o atención de las instituciones públicas, algunas de las cuales enfebrecidas por la mal entendida cultura de masas, han llevado a cabo en el sector editorial una política de competencia desleal, lanzando al mercado productos de alta calidad a bajo coste, encareciendo frente al consumidor los productos, llamémoslos artesanales o independientes. Nos enfrentamos pues a un reto que supone superar los siguientes obstáculos:

1. Competencia deseal 0 indiferencia de las instituciones.

2. Competencia de un mercado establecido bajo las premisas del comercio puro y duro, agresivo, con una fuerte oferta publicitaria y unos mecanismos de distribución que marginan cualquier tipo de producto alternativo.

3. Absoluta falta de infraestructura o coordinación entre los editores independientes.

4. Desfase entre la producción y el consumo en el mismo seno de las ediciones independientes.

A esta serie de problemas quisimos desde el pri- 
mer momento buscar soluciones. Los Encuentros Internacionales de Editores Independientes en sus siete primeras ediciones han profundizado, primero, en el carácter independiente y alternativo de sus propuestas, entendiendo por independientes la elaboración de productos culturales que no se supeditan ni a las políticas culturáles de las instituiciones, ni a la fluctuación del mercado de valores en el sector editorial, dando prioridad al hecho creativo y al proceso de participación, y en segundo lugar entendiendo por alternativos los sistemas de producción, distribución, difusión y venta de estos productos, procurando no gravar el valor de los mismos y creando hábitos de consumo y difusión paralelos a los convencionales. En definitiva supone la creación de un sistema de comercialización y distribución paralelo, que pasa por convertir al consumidor habitualmente pasivo, generalmente una persona con inquietudes culturales, en consumidor activo en ese mismo proceso cultural. El ámbito de esta parcela de la edición independiente es el campo de la cultura en el sentido más amplio, contemporáneo y

Supone la creación de un sistema de comercialización y distribución paralelo, que pasa por convertir al consumidor habitualmente pasivo, generalmente una persona con inquietudes culturales, en consumidor activo. vanguardista de la palabra.

Desde las más convencionales publicaciones de literatura, arte o música, hasta los nuevos lenguajes creacionistas como el mail-art (arte por correo), los fanzines, la poesía visual, los performances o acciones, las instalaciones, la videocreación, la reflexión estética, la música electroacústica, etc. En este sentido se entiende por editor aquel que produce o reproduce objetos culturales sobre cualquier soporte 0 formato, ya sean libros, revistas, vídeos, vinilo, compact disc, cassettes, libros objeto o de artista, series gráficas, cdrom, fotocopias, electrografías, etc. 
La edición independiente utiliza en ocasiones los mismos canales de comercialización de las editoriales convencionales, pero al mismo tiempo genera nuevas redes de difusión y distribución que se ajustan a su propia imágen y filosofía. Al igual que un río, modifica su curso, utilizando siempre el camino más natural y no siempre el más corto. Son numerosas las publicaciones que utilizan otros puntos de distribución alternativos a las tradicionales librerías, como tiendas de ropa, discos, artesanía, bares, galerías de arte, centros sociales y culturales, etc.

Atendiendo a la definición que ya hemos establecido, podemos retraernos en el tiempo y considerar como editor independiente numerosos ejemplos en la historia del siglo XX, baste con citar al propio Juan Ramón Jiménez, autoeditor de sus pequeñas y cuidadas revistas de poesía. Pero en realidad, salvando los movimientos editoriales generados por las primeras vanguardias en los inicios del siglo, son en España durante los últimos años de la dictadura donde se forja el origen marginal y clandestino de ciertas publicaciones, que con la conquista de la democracia, el acceso general a la cultura y la irrupción de las nuevas tecnologías en el campo de la autoedición (fotocopiadoras, ordenadores, vídeos, etc.) provocarán el fenómeno de lo que entendemos por edición independiente. Es precisamente este origen el que marca el sesgo progresista, en el sentido participativo y vanguardista, en el terreno estético de las ediciones.

Los Encuentros Internacionales de Editores Independientes y Ediciones Alternativas nacen el año 1994, a iniciativa de la Asociación Cultural 1900 y con el apoyo del Ayuntamiento de Huelva, la Diputación Provincial de Huelva y la Delegación de Cultura de la Junta de Andalucía, con el fin de iniciar una apoximación y estudio de la realidad editorial y cultural de la que estamos hablando. Con la llegada del Partido Popular al Ayuntamiento de Huelva, los Encuentros se ven obligados a cambiar de sede, 
trasladándose en 1996 a la Universidad Internacional de Andalucía, con sede en La Rábida, y ya en 1997 y con la decidida apuesta del Ayuntamiento de Punta Umbría, que los asume como una actividad estable en su programa cultural, fijan su sede permanente en esta localidad, en la que siguen celebrándose ininterrumpidamente bajo el título de EDITA. En los últimos años los Encuentros han contado con la cobertura y colaboración de otras dos redes singulares Red-Arte (Red de Colectivos Independientes para la Difusión) y GesEDITA que constituye una experiencia singular en el terreno de las ediciones culturales. Su principal característica es la que retoma el ámbito de la periferia como concepto geográfico frente al centralismo que ejerce el medio urbano en el desarrollo y práctica de la cultura. Las pequeñas ediciones culturales articulan un entretejido social de gran calado participativo, a diferencia del diseño piramidal en el que : se sustentan la gran mayoría de los proyectos editoriales de carácter comercial. Esta otra periferia cultural se refrenda en el \begin{tabular}{l}
\hline Los Encuentros \\
Internacionales de \\
Editores \\
Independientes se \\
perciben como un \\
modelo de relación \\
cultural que favorece \\
la cooperación y el \\
intercambio de \\
experiencias.
\end{tabular} marco geográfico, conjugando un binomio físico e intelectual como modelo cultural alternativo en este final de siglo.

Las nuevas tecnologías aplicadas al mundo de la edición, difusión y distribución de los productos culturales, han permitido recuperar zonas deprimidas o distantes de los tradicionales centros donde se asientan las industrias culturales, planteando un nuevo reto en la reordenación y democratización del mundo de la cultura. Esta nueva circunstancia ha permitido elaborar eventos de proyección y dimensión internacional desde poblaciones enclavadas en el medio rural como es el caso de Punta Umbría. 
Cada año se reunen un centenar, aproximadamente, de editores independientes con el fin de presentar sus últimas novedades o plantear proyectos de colaboración y cooperación en el terreno de la difusión y distribución de las publicaciones. También se aborda desde distintas perspectivas la reflexión teórica del proceso social y cultural en el que se enmarca la actividad de estos editores. EDITA es al mismo tiempo un escaparate privilegiado para las últimas tendencias creacionistas, así paralelamente a las conferencias marco, mesas redondas y ponencias, se desarrollan recitales poéticos, conciertos, performances, exposiciones, instalaciones, representaciones teatrales y proyeccions de vídeos.

Como soporte de este movimiento editorial se ha proyectado la creación del Centro de Documentación e Iniciativas Editoriales, cuya finalidad, más allá de su función museística, propone alternativas en el terreno de las iniciativas, coordinación y asesoramiento de los peuqeños editores culturales. El Centro de Documentación es un instrumento que pretende documentar el fenómeno de la edición independiente, así como prestar funciones de asesoramiento y coordinación entre los usuarios del mismo. En la actualidad y a la espera de su construcción, en fase de ejecución, los fondos están siendo catalogados e informatizados para su posterior servicio. El último catálogo de editores independientes se publicó en 1997 y desde ese año, y gracias a la Asociación Cultural Mestizo de Murcia, el directorio de editores independientes cuenta con una página web en internet (http:// www.mestizo.org/editin). Este directorio ordenado alfabéticamente relaciona un total de 750 publicaciones, con información sobre su temática. La estrategia de futuro de este proyecto se basa fundamentalmente en tres aspectos prioritarios:

1. El diálogo con las instituciones públicas para favorecer un cambio en las políicas culturales que facilite el desarrollo y la participación de la sociedad 
civil en estos nuevos procesos de creación, gestión y difusión del arte.

2. Consolidar los recursos que ya hemos puesto en funcionamiento.

3. Coordinar las diferentes iniciativas que en esta línea se desarrollan en diferentes puntos de nuestro país (encuentros, ferias, festivales, congresos, etc.).

Siete años después de la primera convocatoria, los Encuentros Internacionales de Editores Independientes se perciben como un modelo de relación cultural que favorece la cooperación y el intercambio de experiencias, al mismo tiempo que proyecta hacia el futuro una reflexión alternativa sobre los nuevos conceptos del arte y la cultura. Cada día son más numerosos los editores y publicaciones que utilizan internet como un soporte fundamental en la creación y difusión de sus obras, pero también es cierto que con el mismo empeño y entusiasmo el objeto artístico sigue siendo en sí mismo un fin insustituible, más allá de su mera virtualidad. 